\title{
Los de arriba, los de abajo, los de aquí: relatos de la sociedad peruana a través del mural del artista Josué Sánchez en la Casa de la Literatura Peruana
}

\section{LOS DE ARRIBA, LOS DE ABAJO: STORIES OF PERUVIAN SOCIETY IN A JOSUÉ SÁNCHEZ'S MURAL PAINTING AT THE CASA DE LA LITERATURA PERUANA}

Álvaro Iparraguirre Bernaola

Universidad de Lima

\section{RESUMEN}

En este artículo proponemos un acercamiento a la producción artística que se ha ido desarrollando en la sierra central del Perú, centrándonos en uno de los tantos artistas plásticos icónicos peruanos: el huancaíno Josué Sánchez. A través de su trabajo, él ha buscado rescatar la esencia de su cultura e historia y, con eso, construir un estilo y un discurso definidos. Finalmente, elaboramos un análisis pictográfico de una de sus obras más reconocidas, ubicada en la Casa de la Literatura Peruana.

PALABRAS CLAVE: arte, mural, cosmovisión andina, mitología, representación, pintura peruana
ABSTRACT

The text proposes an approach to the artistic production that is being developed in the central sierra of Peru, focusing on one of the many iconic Peruvian artists, such as the Huancaino Josue Sanchez. Through his work, he has looked to recapture the essence of his own culture and history, and also to build a defined style and discourse. Finally, we elaborate a pictographic analysis based on one of his most recognized works, located in the House of Peruvian Literature.

KEYWORDS: art, mural, Andean cosmovision, mythology, representation, Peruvian painting 


\section{UN PAÍS DE RETOS}

Pensar en el Perú es pensar en su cultura milenaria. No es solo hablar de su gastronomía, de su fútbol o de sus paisajes, sino también de su gente y de su historia. Un país lleno de cambios y conflictos sociales, de conquistas y de independencias, de procesos de migración y mestizaje, de resentimientos y reconciliaciones. Sucesos como la conquista del Perú, el conflicto armado interno, el autogolpe del 5 de abril, la muestra de los vladivideos y el Baguazo han cambiado la historia y han marcado la memoria colectiva y lo que construye nuestra identidad nacional. Sin embargo, no todos los sucesos calan de esa manera, por lo que problemáticas constantes como la corrupción, la violencia de género, los conflictos socioambientales, por decir algunos, se convierten en noticia de pocos días, para luego quedar en el olvido.

La identidad nacional se genera gracias a la necesidad humana de identificación colectiva, expresada en dos polos opuestos: (a) en la esfera pública, en forma de discursos construidos por agentes sociales como los medios de comunicación, élites y organizaciones estatales; y (b) en los distintos estilos de vida y sentires compartidos, que usualmente no son representados en la primera (Espinosa y Rottenbacher, 2010). El caso peruano es muy complicado, ya que la convivencia de los distintos grupos multiculturales y multiétnicos define la dinámica social. Según los resultados de la encuesta de autoidentificación étnica, incluida en el último censo realizado por el Instituto Nacional de Estadística e Informática (INEI) en el 2017, poco más del $60 \%$ de peruanos se identifica como mestizo, un $25 \%$ como indígena, un 5,9 \% como blanco y el 3,6 \% como afrodescendiente. Cabe resaltar que "el grupo indígena más numeroso y con mayor identificación propia es el quechua (22,3\%), con más de 5,1 millones de personas mayores de 12 años; seguido del aimara (2,4\%), con más de 548000 personas". Además, alrededor de 80000 peruanos contestaron que se identificaban con uno de los "más de 50 pueblos indígenas que habitan en la Amazonía" (“¿Cómo se autoidentifican los peruanos? Los resultados del censo del INEI", 2018).

Sin embargo, en el mismo artículo periodístico, Newton Mori, representante del Centro de Culturas Indígenas del Perú (Chirapaq), menciona que si bien este porcentaje de personas autoidentificadas como indígenas supera el $3 \%$ que arroja esta encuesta en países como Bolivia, Chile y Colombia, la cifra que afirma que un $60 \%$ de los peruanos son mestizos "esconde un posible rechazo hacia las raíces de sus antepasados y sus costumbres, producto del desarraigo, el racismo y la discriminación", ya que para él, haciendo una lectura amplia de los resultados, se podría aseverar que "el $70 \%$ de los peruanos son, en realidad, indígenas" (“Cómo se autoidentifican los peruanos? Los resultados del censo del INEI", 2018).

Este rechazo viene de la habitual asociación entre raza y clase que ha persistido en países de América Latina: 
Por ejemplo, en el Perú la población indígena de mayoría quechua tiende a ser campesina de los Andes y/o inmigrante urbana insertada en puestos poco calificados del mercado laboral. Los blancos, por otro lado, tienden a pertenecer a las clases medias y dominantes, mientras que ocurre lo contrario con los mestizos y afroperuanos (Gissi et al., 2001). (Espinosa, 2010, pp. 217-218)

De esta manera, persisten las situaciones de desigualdad y exclusión social por género, nivel socioeconómico o por un limitado acceso al poder y educación, las cuales continúan originando conflictos sociales. Sin embargo, tampoco se puede negar el trabajo que se viene realizando para disminuir esta desigualdad, tanto desde el sector gubernamental y de las ONG, como desde el sector privado y, cada vez con más fuerza, desde la sociedad civil. Esta última manifiesta mediante el activismo político los cambios necesarios para que el grupo representado goce de sus derechos y se haga justicia. Esto no solo lo vemos en las distintas marchas que ocurren en plazas y avenidas principales, sino también en expresiones que pueden entenderse al margen de una crítica social, como el arte.

\section{ARTE, REPRESENTACIÓN E IDENTIDAD NACIONAL}

El arte recrea lo social a partir de entender lo dado como una materia plástica y moldeable. Entonces no se trata solo de representar los estratos más profundos de la realidad, sino de imaginar los mundos que allí están contenidos.

(Portocarrero, 2015, p. 8)

En cuanto a las capacidades del arte, Aponte Isaza (2016) resalta una cita de Ember y Peregrine (2004):

Desde el punto de vista de la persona que lo crea, el arte expresa sentimientos e ideas; desde el punto de vista del observador o del participante, evoca sentimientos e ideas. Los sentimientos e ideas de cada una de las partes pueden o no ser exactamente los mismos. Y pueden ser expresados en variedad de formas: dibujos, pintura, grabados, danzas, cuentos, etc. Un trabajo o actuación artística intenta excitar los sentidos, provocar la emoción del observador o del participante. Puede originar sentimientos de placer, temor, repulsión o miedo, pero generalmente no indiferencia. (p. 90)

Así, la autora concluye que el arte tiene como función primaria provocar sentimientos e ideas en el espectador, llevándolo a interpretar algo respecto a lo que ha observado. Sin embargo, al juntar los términos de identidad nacional y arte de manera historiográfica, encontramos que, desde la conquista y el Virreinato, pasando por los años de la República, la mirada se concentraba no en temas que redescubrieran el pasado y la historia, sino en aquellos que imitaran lo producido por Europa, quedando enterradas las expresiones artísticas desarrolladas en tiempos prehispánicos. 
Según Lizárraga (1988), hace poco menos de un siglo, los pintores del Perú enfocaban sus obras en temas de origen europeo, con técnicas orientadas a alcanzar la estética producida en dicho continente. Sin embargo, es el cajamarquino José Sabogal quien, desde la Escuela Nacional de Bellas Artes, decide virar su mirada hacia dentro, hacia su realidad, en busca de una identidad propia. Así, se convierte en el precursor del indigenismo en la plástica peruana, iniciando no solo un cuestionamiento en los temas retratados, sino en la razón de la imagen misma y su discurso. Mirko Lauer identifica dos etapas en el indigenismo:

Durante muchísimos decenios los pintores del Perú pasaron por alto una realidad tan obvia y realizaron sus proyectos como si el rol social y cultural de la plástica en el Perú fuera el mismo de Europa. El rechazo de ese rol europeo ha sido en su primera etapa - que se inicia con los rudimentarios trazos del indigenismo- solo un reflejo de la tarea descubridora de nuestro pueblo que realizó la intelectualidad peruana en su conjunto; recién en un segundo momento se produjo la conciencia de que la tarea es más compleja que el rescate del indio peruano como tema de arte, de que se trataba más bien del rescate de la imagen misma, de la función plástica en su conjunto. (Como se citó en Lizárraga, 1988)

Lizárraga (1988) sostiene que, si bien ambas generaciones lograron plasmar realidades procedentes del interior del país y plantear el cuestionamiento de la función plástica, ninguna reconocía la importancia de los orígenes estéticos andinos. Aún no se lograba sostener una base teórica que uniera el arte erudito con el arte popular como un solo concepto, por lo que el arte andino seguía siendo marginado en su propio espacio geográfico. Incluso con la revalorización del arte popular por parte de Sabogal y su posterior designación como director de la Escuela Nacional de Bellas Artes en 1932, se mantuvo una enseñanza conservadora y limitada a seguir técnicas asociadas a principios estéticos europeos. Es en la década de 1980 cuando la arqueología, la antropología y la historia comienzan a transformar la cultura peruana debido a hallazgos que permiten recuperar técnicas andinas. La Escuela Nacional de Bellas Artes, luego de atravesar diversas crisis y desacuerdos, logra marcar un rumbo más claro en los años de 1984-1985, con la introducción de cursos teóricos como antropología y realidad nacional, en busca de desarrollar una expresión nacional en la plástica. Así, surge una tercera generación que "toma como fuente propia tanto el textil antiguo en términos de medio e iconografía, como la mitología, la geología y la geografía andinas en términos de tema"; su enfoque ya no se dirige necesariamente hacia un arte indigenista, sino hacia uno andino (Lizárraga, 1988).

Por su parte, Lauer (2007) resalta la evolución de la pintura del siglo xx en las manifestaciones de los grupos dominantes peruanos, la cual "va de un Perú dominado

1 Para este artículo se ha revisado la segunda versión del libro Introducción a la pintura peruana del siglo xx, publicada en el 2007. La versión original es de 1976. 
por una oligarquía tradicional [...] a otro en que el poder se manifiesta como una lucha continua entre diversos sectores de la burguesía por una hegemonía interna a la sombra del capital norteamericano", dejando una posición subordinada del indio en la plástica ${ }^{2}$. En Crítica de la artesanía: plástica y sociedad en los Andes peruanos (1982), Lauer también señala la alienación artística por parte de la hegemonía y su designación de lo que es arte o no, creando un sistema que funciona como mecanismo básico de dominación cultural. Así, concluye:

En tres cuartos de siglo la pintura peruana ha tratado de representar el mundo en general y el país en particular, y en cada etapa ella ha "cambiado de manos", ha variado su perspectiva, sus intereses, su problemática; pero siempre representar la realidad ha sido el eje fundamental de su actividad, en torno del cual se han ordenado las escuelas y las polémicas. [...] Hemos visto también cómo los diversos cambios en los temas centrales de la representación corresponden a modificaciones sociales profundas y a importantes transformaciones de la conciencia local. Si para Platón "cuando el ritmo de la música cambia, los muros de la ciudad tiemblan", en pintura es el cambio de una temática por otra el que acompaña a las grandes transformaciones sociales. (Lauer, 2007)

El investigador Manuel Baquerizo (2009) postula que hay dos posturas que dividen el arte peruano: la que tuvo influencia del arte europeo de vanguardia (con su exploración de los mundos interiores y las emociones puras) y la tradición milenaria de la cultura andina, notable por sus símbolos y contenidos míticos. Lizárraga (1988) hace la misma distinción, pero desde los instrumentos usados: por un lado, lo occidental, de origen europeo, en el que primó el figurativismo y se manifestó esencialmente en la pintura, la escultura y el grabado; por otro, lo americano, de origen andino, donde primó el simbolismo y su manifestación se dio principalmente en los textiles, las cerámicas y los trabajos en piedra y metal.

Los avances en materia de investigación realizados por ambos autores son importantes para entender los procesos y las transformaciones del arte en el Perú. Lizárraga (1988) indicaba la necesidad de unir el arte erudito con el arte popular, ya que lo andino como concepto social y cultural aún sufre de marginación, incluso en su propio espacio geográfico, prolongando las brechas sociales y complejizando el reto de la distancia:

[...] haciendo necesaria la articulación dentro de un contexto nacional, individual y multidisciplinario de integración [con] [...] un lenguaje que no es ni quechua, ni aimara, ni español, sino andino, peruano y panamericano, como la redefinición de la palabra artista de pintor de cuadros a el/la que pone en orden la realidad. (p. 16)

2 En el libro mencionado hay un capítulo titulado "Representación y cultura dominante" en el que ahonda sobre este tema. 
Hay una necesidad muy clara de descentralizar y no considerar el arte peruano andino como inferior, como en varios momentos se le ha tratado de juzgar.

En la actualidad, se puede atisbar cierto optimismo en la realidad limeña, donde una naciente proliferación de artistas evidencian sus orígenes o influencias de raíz andina o amazónica. Sin embargo, es preciso advertir que esto puede caer en una mera apropiación cultural, al tomar elementos propios de una cultura minoritaria y/o vulnerable para ser usados por una cultura dominante fuera del contexto de origen y con otros fines. Esto es lamentable en el sentido de que no se produce un intercambio entre ambas culturas, sino que la expresión se convierte en un elemento exótico y una tendencia comercial, mas el grupo que la produce continúa invisibilizado y marginado, perpetuando la desigualdad.

Si bien es urgente la descentralización en aspectos sociales, económicos, culturales, etcétera, la representación y visibilización de estos grupos en la capital también es necesaria para acercarnos a realidades que aún se consideran incomprensibles e incluso primitivas, a fin de reconstruir una nación que nos identifique y sea consciente de la extensión por la costa, sierra y selva. No se pretende una homogeneización, sino un reconocimiento. Al revalorizar el arte en sus diversas expresiones y representaciones, se legitima la identidad que no es de la capital ni de Occidente, que desde la conquista ha sido denigrada y ubicada como inferior, lo que ha incitado un resentimiento nacional y vergüenza de los orígenes y prácticas no occidentales. No obstante, es importante cuestionar el estado de las cosas y encontrar la manera de que los avances no se conviertan en solo tendencias, sino en algo constante: que represente y haga sentir, que genere empatía y reconocimiento, que cuestione y revolucione, que nos quite las vendas de los ojos y la idea de que el Perú es Lima y lo demás solo sirve para Lima. Somos parte de una cadena, no somos uno sin el otro.

\section{UN ACERCAMIENTO A LA COSMOVISIÓN ANDINA}

De la semilla dormida tanto tiempo, comienza a salir raíces...

(Lizárraga, 1988, p. 16)

Hablar de lo "andino" resulta complejo, especialmente si se le quiere definir en términos y características exactas, o limitándolo a lo indígena. Como todo grupo que interactúa con otro, sufre variaciones y mestizajes que impactan en el desarrollo de su identidad y sus expresiones. Limitar la identidad andina a una existencia restringida al pasado y a lo rural es perpetuar mecanismos de dominación, fomentando el rechazo y la negación de cambios sociales y su incorporación a las ciudades, así como a dinámicas modernas de participación en el mercado (Kingman, 1992). 
Sin embargo, cabe resaltar que los procesos de globalización han llevado a invisibilizar los conocimientos y logros alcanzados en la convivencia entre el hombre y la naturaleza en los Andes. Antes de la conquista, el hombre andino tuvo que dominar la naturaleza para su supervivencia, desarrollando prácticas como la domesticación de plantas y animales, la creación de un sistema de irrigación y la construcción de andenes, etcétera, a diferencia del modelo europeo que buscaba el perfeccionamiento de herramientas para efectivizar el trabajo, siendo la productividad el eje de su desarrollo. En el mundo andino prehispánico, las técnicas eran simples y se aprovechaba lo que la naturaleza podía ofrecer, estableciendo como base de su desarrollo la cooperación (Golte, 1992). Este aprovechamiento y cierta dependencia del entorno llevaron a las prácticas de ritualización y la percepción de tiempos permanentes en su cosmovisión.

A lo largo del proceso prehispánico, considerando las variaciones regionales y temporales, la religión andina se fundó en una "tradición recolectora y cazadora, basada en creencias en espíritus y fuerzas trascendentes que regulaban los cambios astronómicos, naturales y sociales" (Santos, 2009). De esta manera, se construyen como deidades el sol, la tierra, la lluvia, las montañas, los ríos, las lagunas, etcétera, personificadas luego en el cuerpo humano de gobernantes y en los cuerpos de animales como el cóndor, el jaguar y la serpiente. Es así como la adaptación a su entorno, gracias a los conocimientos acumulados por la convivencia con la naturaleza, llevó al hombre andino a crear ritualidades cimentadas en el carácter mágico de la caza, la fertilidad agrícola y los sistemas de cooperación comunal. De ahí la importancia del culto a los antepasados y de establecerse en un espacio delimitado a lo largo de generaciones, así como de controlar sus recursos naturales.

En esta cosmovisión, la religión y la naturaleza cobran mucha fuerza, por lo que, según esta manera de pensar, el mundo se manifiesta como una dualidad. Cielo e infierno forman parte de un mismo espacio; el bien y el mal están presentes en un mismo elemento así como el yin y el yang, polos opuestos que se complementan, no se mezclan, pero forman unidad. Se percibe una manera de ver el mundo manejada por dos fuerzas necesarias y que forman una sociedad tripartita: el Hanan Pacha, el Kay Pacha y el Uku Pacha. El Hanan era considerado el mundo de arriba, lo celestial; el Kay es el mundo de aquí, en el que habitamos; y el Uku es el mundo de los subsuelos, de las minas, del infierno, el mundo de abajo. No obstante, la separación entre pachas o mundos no es absoluta, sino que permite la constante interacción entre uno y otro. Este concepto de complementariedad sirve de base a una ética-estética andina desarrollada desde épocas precolombinas, límite mutuo de los complementos, definida como lo que genera vida (Díaz, 2003, p. 287). A pesar de estas divisiones, los hombres, los animales, las plantas y los seres mitológicos conviven unos con otros, dándoles un valor igualitario a los diversos individuos que conviven en las obras. Existe una "analogía entre lo real y lo sobrenatural, lo conocido y lo desconocido" (Milla, 1990, p. 8). 
A partir de la conquista del Perú, el choque entre la cultura andina y la española generó una lucha de estructuras y categorías vigentes en ellas. A los españoles se les imposibilitaba la comprensión de una lengua y una escritura diferente de la occidental, por lo que los misioneros iniciaron el propósito de integrar a los indígenas al cristianismo mediante la producción de un mecanismo de comunicación con ellos y la extirpación de sus idolatrías y ritualidades. Esta comunicación era reforzada por imágenes del alma glorificada y del alma condenada, así como la cruz, símbolo principal de esta nueva religión (Melia, 1975). De esta manera:

Su empleo estuvo orientado a convencer a los indios de cuán equivocados habían vivido. Que sus dioses no eran dioses, que sus costumbres, apartadas del buen vivir, y que ellos, los sacerdotes del verdadero Dios, les traían la verdad que iluminaría sus vidas y los llevaría a la salvación eterna. Era un mensaje de profundo contenido etnocéntrico y de clara vocación etnocida. En el lenguaje de Melia, los misioneros se comportaban como si el pecado estuviese en la condición de ser indio. (Pinto, 1992)

Sin embargo, pese a esta represión progresiva, los indígenas buscaban adaptarse a este nuevo orden y, a su vez, resistir y conservar su identidad. Así, producciones como la música, la danza, los ceramios, muros, metales y textiles no fueron tan controlados en su elaboración y significación cultural, pues cada uno tenía un lenguaje propio desarrollado siglos antes de la conquista, lo que permitió la transmisión de mensajes y conocimientos que no pudieron ser descifrados por los españoles y llegaron a mantenerse vigentes hasta hoy. El textil fue el caso más claro de resistencia, a pesar de la introducción de nuevos mecanismos para tejer, la prohibición de la tejedura de ciertos dibujos y el uso de cierta vestimenta, ya que "los conquistadores jamás sospecharon que en el mismo corazón de los textiles (los entrecruzamientos de los hilos y el modo de realizarlos) se hallaban informaciones más o menos conscientemente codificadas" (Desrosiers, 1997).

Otra forma de resistencia fue la apropiación de elementos de la cultura dominante a través de una interpretación propia. Por ejemplo, hacia 1582, Francisco Tito Yupanqui, nacido en Copacabana, Bolivia, esculpió a la ahora conocida Virgen de Copacabana tomando como referencia a la Virgen de la Candelaria de España; sin embargo, la escultura no fue bien recibida en un inicio, pues las obras eran valoradas según estéticas y técnicas europeas que los artistas locales no lograban alcanzar. Pero lo más resaltante fue el ansia del poblador andino por hacer propio aquello que le era ajeno y que le fue impuesto como dogma:

Si estos indios ya habían sido verdaderamente cristianizados, el deseo de dar a su pueblo una imagen puede mostrar simplemente su devoción; pero la insistencia en que esa imagen fuera hecha por ellos mismos puede entenderse como una apropiación de la Virgen, a la cual le quieren dar su propia expresión, e incluso su propio sentido cultural. (Salles, 1992) 
También se perciben intentos de sincretismo para sustituir a las deidades presentes en la identidad andina mediante su fusión con deidades cristianas. La presencia de haces de luz y la irradiación pueden hacer referencia a lo que el sol representaba: una señal sobrenatural y de divinidad. Un intento más claro es el de las iconografías que representan a la Virgen y a la Pacha Mama como una sola. Sin embargo, estos intentos, así como las apropiaciones hechas por parte del poblador andino, no lograron eliminar tanto rituales y cultos a la tierra o el sol como prácticas religiosas cristianas.

En consecuencia, la religión de los pueblos andinos contemporáneos se funda en la "compleja interacción teológica entre los elementos originales y los cristianizados desde fenómenos e ideologías históricamente producidos, tales como imposición, interpenetración, extirpación, sincretismo, resistencia y reinvención" (Santos, 2009). De esta manera, se construye una cosmovisión compleja, que manifiesta conocimientos y sentires respecto a cómo se ha ido percibiendo y viviendo el mundo, la cual está representada en símbolos, mitos y rituales.

Por lo tanto, como se ha mencionado anteriormente, dentro de esta cosmovisión andina hay ciertos elementos que se vuelven relevantes y recurrentes en las diversas expresiones artísticas. Estos tópicos buscan significar elementos del mundo real en uno simbólico. Por eso concluimos citando a Lizárraga (1988):

Hablar de la estética divorciada de la ética es considerar el arte en el contexto limitado del taller, la galería y/o el museo, segmentando el concepto de creación de la comunidad; descontextualizando la obra de arte en sí de la cultura, en su significado total [...]. Por eso, cuando se hace una consideración del arte es necesario relacionar al creador con su medio ambiente; es preciso hablar de espacio, percepción y expresión. Tocar estos temas es, finalmente, acercarse al campo del patrimonio cultural. (p. 20)

\section{ANÁLISIS PICTOGRÁFICO VISUAL DEL MURAL DE JOSUÉ SÁNCHEZ EN LA CASA DE LA LITERATURA PERUANA}

Para profundizar en este estudio, analizaremos el mural elaborado por el autor Josué Sánchez que se encuentra en la Casa de la Literatura Peruana (figura 1). Este análisis sigue las tres etapas propuestas por Panofsky, por lo que se enmarca en una metodología clásica y formalista de la historia del arte.

Cabe mencionar que este mural nació como un encargo, pues querían que Sánchez grafique la historia de la literatura peruana, incluyendo a los más grandes escritores que hayamos tenido a lo largo de nuestra historia. Una de las particularidades que salta a la vista es una pilastra que se encuentra al lado izquierdo, en pleno mural. Sánchez nos comenta que esta se encontraba ya en la pared, así que tuvo que ver la manera creativa de utilizarla. Y lo hizo: creó otra pilastra, en este caso dentro de su pintura, al lado 
derecho, y ambas sirvieron como separaciones de los diversos ambientes o escenarios de la obra. Es así como el artista se apropió del espacio, de manera inteligente, y pudo distribuir el contenido a su forma y estilo. Este mural le tomó aproximadamente tres meses de trabajo y está abierto al público, pues forma parte de la exposición permanente Intensidad y altura de la literatura peruana.

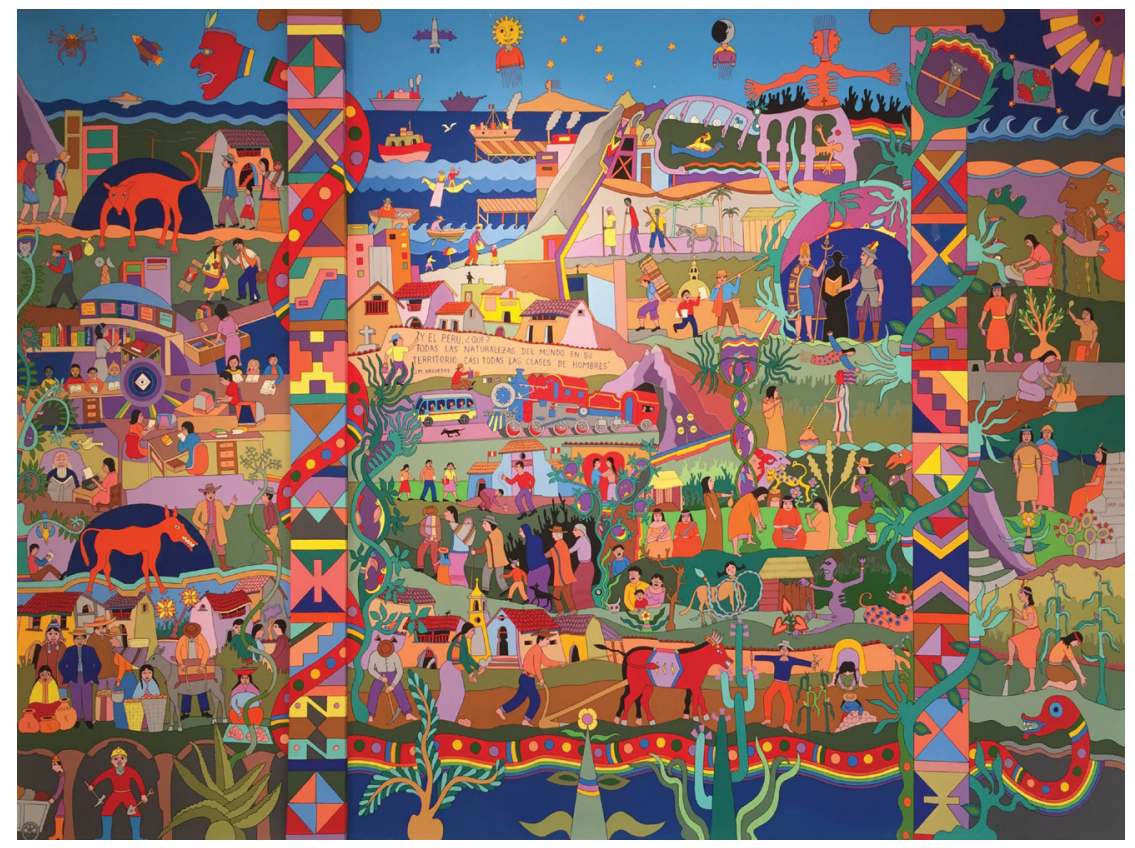

Figura 1. Mural de Josué Sánchez en la Casa de la Literatura Peruana Fuente: Casa de la Literatura Peruana (2015)

\section{Análisis preiconográfico}

El soporte de la obra es el mural y la técnica es la del acrílico. El formato es rectangular y mide aproximadamente veinte metros cuadrados. El mural se extiende dentro de tres espacios verticales separados por dos pilastras que estructuran todos los elementos que integran la obra. Es interesante resaltar cómo el artista ha tomado estas dos pilastras estructurales de la pared sobre la que está trabajada para usarlas como separadoras de los elementos visuales que forman el mural. Hay que tener presente que estas están decoradas con elementos preincaicos que las rodean y cuya forma es orgánica y no geométrica. Se hace énfasis en lo ondulante y circular. Esto también se puede observar: las líneas ondulantes abundan en el diseño del dibujo general.

En el mural podemos encontrar una subdivisión interna: cada espacio de los tres verticales está dividido en tres zonas que denominaremos inferior, media y alta. Por 
otro lado, no se ve que el artista haya empleado una perspectiva geométrica o aérea. Tampoco se observan líneas de fuga que construyan profundidad al interior de los espacios representados: aquí se trata más bien de reforzar la planitud (planimetría o bidimensionalidad) de las figuras. Este aspecto está reforzado por el trazo armónico con que el artista ha trabajado las figuras: las líneas inician y terminan en el mismo punto, marcando los bordes, sin trabajo de algún tipo de difuminado o sombras, por lo que las figuras adquieren una contextura física particular, marcada y robusta. El espacio representado no se "va hacia el fondo", como ocurre con las obras de tipo ilusionista que emplean la profundidad y las líneas de fuga, sino que más bien aquí el espacio se trae hacia el frente. No se priorizan elementos, sino que todo es importante, todo es traído hacia "el frente", hacia el espectador.

Respecto a la composición, es simétrica en cuanto a la estructura general del mural: son dos espacios a los laterales y uno central más amplio, en sentido simétrico. Sin embargo, cada uno de estos tres espacios está trabajado con una composición asimétrica. El color, por otro lado, se produce haciendo énfasis en los tonos enteros, de una saturación media y con una luminosidad media-alta: esto es importante porque nos deja ver que el artista ha empleado el color casi puro, sin gradaciones cromáticas. La paleta de color (figura 2) está estructurada principalmente por los azules, verdes y marrones (que en la mayoría de los casos llegan a rojo).

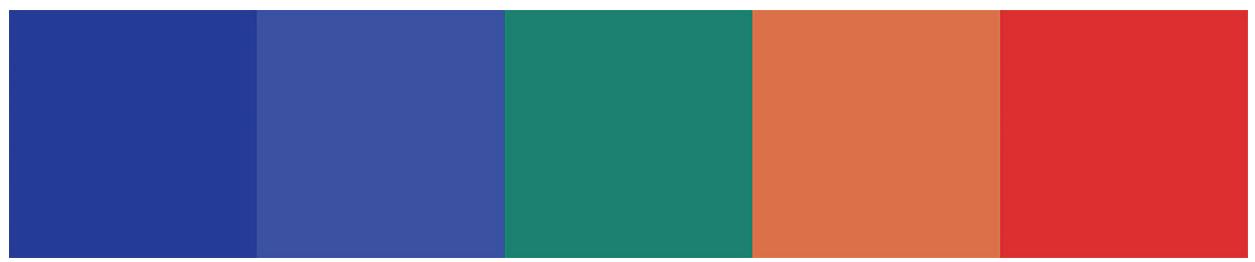

Figura 2. Gama cromática obtenida utilizando la aplicación Adobe Capture sobre la misma obra del artista

Por último, resalta el movimiento de las figuras, mientras que las dos verticales (pilastras) no compiten con la gran cantidad de líneas sinuosas al interior del mural. Estas líneas son principalmente vegetales, e incluso en elementos arquitectónicos (casas y edificaciones) y objetos (embarcaciones, carros de carga, materiales de trabajo, etcétera) son trabajadas sin hacer énfasis en la "geometricidad" de estos. Se prioriza la línea sinuosa y serpenteante sobre la geométrica y angulosa. Finalmente, la iluminación para todo el mural es uniforme, continua, todo está pintado para ser visto y todo está dispuesto para estar iluminado. 


\section{Análisis iconográfico}

Josué Sánchez nació en Huancayo en 1945. Estudió formalmente en la Escuela de Bellas Artes de la Universidad Nacional del Centro del Perú. Su producción artística privilegia el empleo de la vida campesina, elementos prehispánicos (como motivos mochicas, nascas y tiahuanacos), manifestaciones de arte popular (mates burilados, textilería y cerámicos andinos) y la tradición cristiana. Su temática está fuertemente inmersa en la vida campesina comunitaria del valle del Mantaro y también de las regiones del sur andino. Si bien en gran parte de su producción representa al poblador andino en el mundo rural, no deja de lado el contacto (o choque) cultural que este tiene al vivir en constante roce con la modernidad, la Iglesia católica, los problemas sociales, entre otros. Sin embargo, cuando el artista pinta la vida campesina, lo hace de forma lírica, libre de los marcos europeos y de la representación ilusionista, matemática ${ }^{3}$. Sánchez es un artista que privilegia la espontaneidad en sus obras, a tal punto que prefiere realizarlas directamente sobre el soporte, sin necesidad previa de bocetos o dibujos preparatorios.

Su producción muestra dinámicas en función de la relación del hombre con las plantas, los animales, el paisaje, la gente de la comunidad e incluso la muerte 4 . Asimismo, representa las relaciones comunitarias como los rituales, las fiestas, las reuniones, el trabajo y las situaciones sociales más complejas. En su obra se integran también elementos de la costa, la sierra y la selva. No se puede dejar de mencionar que gran parte de sus últimas producciones se han centrado en temáticas de violencia, como en Ayacucho y Selva trágica. En este sentido, es un artista que no se mantiene al margen de estos hechos, sino que los incorpora en su obra con la finalidad de visibilizarlos para dar voz y presencia a aquellos que cayeron en el enfrentamiento que se produjo en los años del conflicto armado interno. Por otro lado, cuando Sánchez trata el tema pastoril, también lo hace, en algunos casos (como en Amaru dorado I y Amaru con peces), mostrando un espacio simbólico sin conflictos, pacífico y en eterna comunión. Por último, cabe señalar que todo esto lo realiza dentro de una visión mítica, sin dejar de lado la cosmovisión andina que atraviesa su obra.

El trabajo de este artista no elude la confrontación entre el mundo andino en su estado nativo y la tradición occidental. Esto se evidencia en la bidimensionalidad de sus superficies, la robustez de sus figuras, la narración paralela sin supeditar las secciones de sus obras a un orden jerárquico compositivo. Para el artista importan todas las

3 Usamos la palabra matemática para enmarcarla dentro de la concepción occidental de la perspectiva, como el resultado de años de estudios de la geometría y la matemática que llegó a consolidarse en el Renacimiento. La usamos también para oponer de alguna manera esta representación más "académica" frente a la autodidacta, empírica.

4 Los motivos son fácilmente reconocibles, por ejemplo, los tejidos, las esculturas andinas, los motivos animales como las serpientes, el zorro, el cóndor, el búho, los peces, el ganado, entre otros. 
figuras, todos los elementos tienen vida y todos cumplen una función en este mundo andino: interesa lo de arriba, lo del medio y lo de abajo. Entre sus obras más conocidas se encuentran los murales de la iglesia de Chongos Alto (Huancayo) y el mural realizado para el convento franciscano de Santa Rosa de Ocopa, en el que destaca la labor de las misiones de evangelización en la selva peruana.

\section{Análisis iconológico}

Al contemplar el mural de Josué Sánchez, podemos observar que nos envuelve debido a sus dimensiones y nos describe una multiplicidad de situaciones que se distribuyen en toda la superficie. Como mencionamos anteriormente, los colores y los bordes de las figuras y objetos están representados haciendo énfasis en la corporalidad de su anatomía y su fisicalidad: los objetos y las personas tienen peso, reclaman su posición en el mural, están hechas para verse siempre lo más próximas posible al espectador. El que las figuras y los objetos estén hechos para reforzar su bidimensionalidad significa que el autor intenta presentar la superficie del mural lo más próxima posible al espectador y, en esta línea, la superficie del mural son las figuras, los elementos, los colores. No hay ilusiones que descifrar, todo está claro, todo es directo e incluso podría decirse que todo está dicho para que impresione al espectador, no por la forma (o técnica), sino por el contenido. En este sentido, la dimensión del mural tiene mucho que jugar aquí.

Por otro lado, el mural nos habla de las escenas de la vida del mundo andino: la educación, la familia, los bailes, la lectura ${ }^{5}$, del zorro de arriba y de abajo, del patrón y el campesino, de la minería, el sol y las estrellas, los aviones, la pesca, la playa, los edificios, las fábricas, las casas rurales, el transporte, las relaciones comunitarias, el amor, la inmigración, la muerte, la siembra, la cosecha, la luna, los dioses, el encuentro entre el inca y el español mediado por una sombra (la Iglesia, sin rostro) y el encuentro entre el hombre andino y los turistas. Constantemente se hace alusión a la dualidad, al encuentro. Todo esto ocurre bajo un cielo dominado por el sol y la luna, sostenido por las dos pilastras que funcionan como soporte del mundo. Nótese que estas, además de separar, también unen: dividen en tres espacios el mural, pero al mismo tiempo lo articulan a modo de retablo. El mural puede leerse desde este punto de vista como un retablo con las dos puertas abiertas. Cabe señalar, además, que las dos pilastras están diseñadas con elementos geométricos, a diferencia del resto de figuras y elementos del mural; esto tiene sentido por cuanto los soportes de toda construcción tienen que ser geométricos ${ }^{6}$. Finalmente, en su decoración, aparece una especie de serpiente de dos

5 No en vano este mural está ubicado en la Casa de la Literatura del Perú.

6 Sin embargo, es interesante notar que las dos pilastras están rematadas en sus lados superiores con dos volutas, que hacen referencia más a pilastras occidentales que a locales o andinas, las cuales no tenían estos elementos. 
cabezas (en la de la izquierda) y elementos vegetales (en la de la derecha). La serpiente de dos cabezas, que tiene un rol vital dentro de la cosmovisión andina, refuerza la función de las pilastras, separando y a la vez uniendo todo, dándole unidad a la obra.

En esta obra, a diferencia de otras del artista, los elementos no se centran en una cuestión simbólica, salvo las figuras mitológicas como el sol o la serpiente. El resto es referencia directa, es vida: del campo y de la ciudad. La sección izquierda del mural prioriza los temas de la educación y el encuentro entre lo andino y lo occidental, el trabajo en la mina, la relación laboral e incluso la tecnología moderna, como el cohete que está volando sobre el cielo. En este sentido, podemos interpretar esta sección como el presente y el futuro, mientras que la sección derecha del mural hace énfasis en diseños que sugieren el pasado: la vestimenta incaica, la relación con los dioses, la relación del inca y el cultivo del maíz. La sección central prioriza de alguna manera el encuentro entre ambas secciones sin dejar de estructurarse en tres: el Hanan Pacha, el Kay Pacha y el Uku Pacha.

Además, se puede observar la constante repetición de elementos vegetales, que remite a la gran identificación con la naturaleza, característica de la cosmovisión andina. En cambio, la referencia a los animales es más reducida, sin que haga falta retratar al cóndor, el ganado y el zorro. En cuanto al trabajo con el color, como se dijo anteriormente, las líneas intentan contenerlo en las formas: esta dualidad entre color y líneas que lo demarcan hace notar la presencia del color en mayor intensidad. En esta obra vemos que los colores se encuentran en estado puro, lo cual no se debe atribuir a la ausencia de pericia, sino a un consecuente empleo de la materia prima (el color), quizá el mismo estado puro al que se alude en el mural: la naturaleza, el mundo animal, los elementos geográficos e incluso tanto hombre como mujer. El tema lo leemos en clave de una pureza de la representación de los elementos de la naturaleza, pureza que está de acuerdo con la jerarquía que el autor otorga al color y la simplicidad (leída como naturalidad) en el dibujo en todo el mural.

Por lo expuesto, esta obra es una representación unificada de las múltiples miradas y relaciones del hombre andino hacia sí mismo y hacia aquello que le es ajeno, pero creemos que la enunciación proviene del hombre andino: sin artificios que distraigan el tema. En este sentido, el artista representa a seres vivos con una visión llena de vitalidad que hace del mundo un todo vivo, hace de su mural una representación viva del mundo. 


\section{JOSUÉ SÁNCHEZ Y SU REPRESENTACIÓN DEL MUNDO ANDINO7}

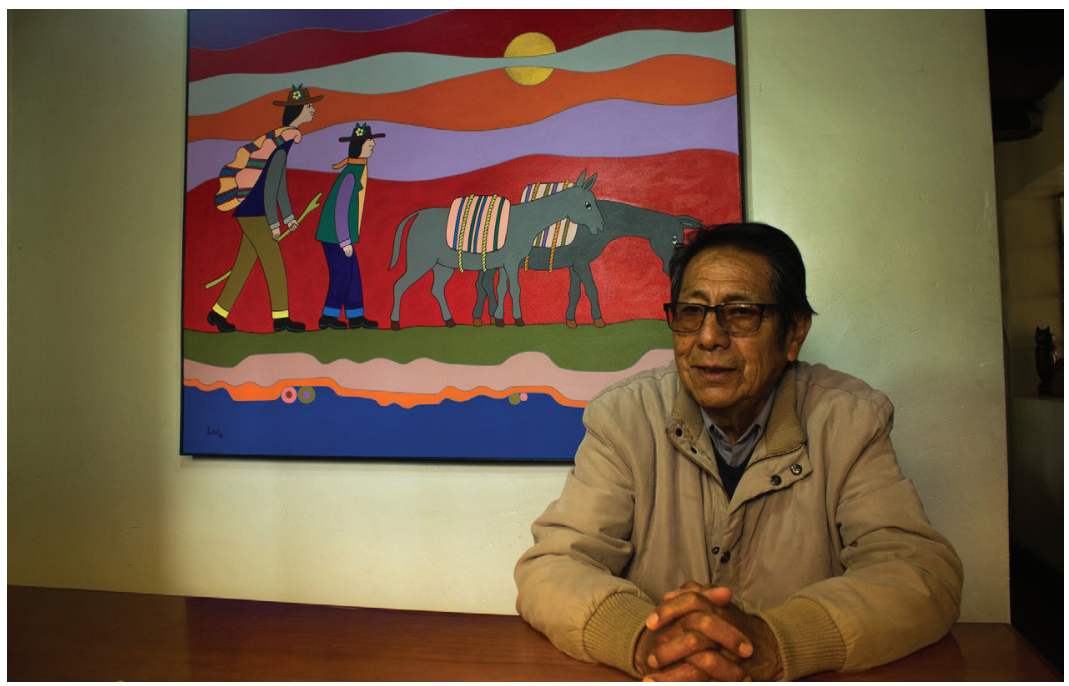

Figura 3. Josué Sánchez en su casa en Huancayo

Fotografía: Álvaro Iparraguirre Bernaola

“Un mural está por encima del autor”, reza Josué Sánchez (comunicación personal, 16 de septiembre del 2017). Para el artista, las historias son capaces de trascender y generar diálogo con el público. Un diálogo que, hasta cierto punto, se presenta de manera metalingüística, pues estamos hablando del diálogo con el público a través de una obra que precisamente nos muestra eso: diálogo entre sus elementos. A diferencia de la pieza artística que suele montarse en una galería o en un espacio privado, un mural es, usualmente, de libre acceso y dirigido al transeúnte, lo que genera interacción y juicios distintos. Además, su permanencia en el espacio es menos frágil que alguna otra obra que pueda ser instalada y removida de una galería. Por lo tanto, la obra como tal no será el fin, sino el camino para una conversación; una conversación no pasiva, sino una que genere debate y, para que ello ocurra, es necesario cuestionar. Sánchez es un fiel creyente de que, para trascender, hay que criticar, por lo que es necesario estar cerca del pueblo. No en vano el artista ha mantenido su residencia y centro de trabajo en Huancayo, sosteniendo una temática constante a lo largo de estos años, centrada en el mundo andino, lugar recurrente de sus obras.

Originario de Huancayo, Josué Sánchez vive a unos diez minutos del centro de su ciudad natal, entre el valle del Mantaro y la urbe. En su casa también está ubicado su

7 Agradezco a Josué Sánchez el haberme abierto las puertas de su casa-taller y permitirme conocer de cerca el proceso y los lugares en los que trabaja. Hay mucha historia alrededor de su obra. 
taller, un lugar bastante espacioso y amigable a la vista. El arte brota de cada rincón de su hogar y es que desde su infancia estuvo en constante contacto con las artes:

De niño vivía cerca de una fábrica de tejas que nos daba una propina a los niños por trabajar en terracota pequeñas esculturas de toros, leones e iglesias que la fábrica obsequiaba a sus clientes. Era divertido hacerlas. [...] Otra cosa que debió influir fue la afición de mi madre a urdir mantas. Yo le ayudaba a seleccionar los hilos. Así aprendí a armonizar los colores. (Sánchez, 2006)

De pequeño quería ser músico debido a sus vivencias y experiencias en un entorno eclesiástico, ya que su padre fue pastor evangélico. Posteriormente, ingresó al Conservatorio, pero tuvo que dejar ese sueño para cuidar a su madre, quien había enfermado gravemente. Más tarde, ya en Huancayo, se decidió por estudiar escultura en la Escuela de Bellas Artes de la Universidad Nacional del Centro del Perú. Allí, como menciona, solo eran dos los que estudiaban esa carrera, por lo que el taller estaba a su disposición y eso le permitió desarrollar un estilo propio. Durante sus estudios se encontró aliviado de estar lejos de la pintura académica -limitada a técnicas y estéticas occidentales- que se practicaba en la escuela, y un año antes de culminar su carrera realizó su primera exposición de pintura. "Entonces me preguntaron por qué pintaba $y$, un poco en serio, un poco en broma, contesté que era por fastidiar a los pintores", sostiene el artista (Sánchez, 2006).

Su estética, muy marcada desde sus inicios, dota de ritmo y frescura a su obra, en la que concibe al mundo como un organismo vivo. Si bien cuenta con un estilo propio, Josué Sánchez recoge el trabajo realizado por sus antecesores de esta parte de la sierra, especialmente por Alejandro González Trujillo (1900-1985), más conocido como Apu-Rímak, quien fue su maestro y elogió su trabajo, alentándolo a seguir experimentando. La influencia pictórica es evidente: colores, trazos y el rechazo a la perspectiva es lo que más resalta a los ojos. A su vez, Apu-Rímak rescata esta estética del textil precolombino de esta zona del Perú, que buscaba asemejarse a los colores de la naturaleza y a lugares emblemáticos con mucha fuerza visual, como el valle del Mantaro, para aproximarlos a sus obras. Según el arqueólogo Hermilio Rosas, en su discurso de inauguración de la exhibición El textil andino: herencia por conservar, "el pueblo andino se ha identificado a través del tejido desde lo cotidiano a lo sagrado. El tejido era el conductor que entramaba todos los aspectos de la vida individual y colectiva" (como se citó en Lizárraga, 1988, p. 39). Por su parte, Baquerizo (2009) sostiene que "se hace presente una estética que podría llamarse andina, porque busca su inspiración en los tejidos, en la cerámica y en los mates burilados. En lo que tuvo mucho que ver el magisterio del pintor Apu-Rímak".

Pero Sánchez tampoco es ajeno a Occidente. En su búsqueda de una imagen peruana, reconoce su gusto por grandes artistas de Europa. Resalta elementos de El Bosco, que se plasman en la manera de estructurar sus murales; hay mucha información en ellos y no 
se concentra en un solo punto de vista. También rescata a Bruegel, por la gran cantidad de elementos en su composición; a Gauguin, por el uso de los colores fuertes y rojos intensos; a Rodin y a Miguel Ángel, por su perseverancia y trabajo constante. "Y no está tampoco mal, [en sus propias palabras], la locura de Van Gogh" (Sánchez, comunicación personal, 16 de septiembre del 2017).

Además de su marcado estilo visual, hay que detenernos en su estilo temático. Tal como comenta Milla (1990), el arte andino se ha valido generalmente de "un entorno natural y social y que se presenta en la iconografía naturalista. Hombres, animales y plantas conviviendo en un mismo hábitat fueron motivo permanente de estilización" (p. 8). Sánchez es el artista de lo cotidiano, de lo que ocurre a diario en el mundo rural. En todo artículo y entrevista (Acevedo, 2013), afirma que el valle del Mantaro es su raíz y su fuente. Es su centro de inspiración y su eje temático a lo largo de toda su carrera.

Josué Sánchez ha seguido la temática de su antecesor, priorizando el discurso y contenido antes que la forma. En ese sentido, las representaciones del artista no solo visibilizan una realidad, sino que tienen como materia central la búsqueda de la identidad andina, por lo que es de gran importancia del contexto social, cultural y económico. El artista aclara:

Lo que he querido plasmar en mis pinturas es el contenido temático, actualmente no se trabaja con el tema, el contenido de mis pinturas es la tripartición del mundo andino. Yo me encuentro en una búsqueda de lo nuestro. En el total de mi obra resalta lo temático, lo andino. El contenido más que la forma. Mi influencia viene de las culturas preincaicas. Es innegable que en cuanto a la vía occidental el material sea uno de los soportes principales, pero eso es superficial. (Como se citó en Díaz, 2003, p. 288)

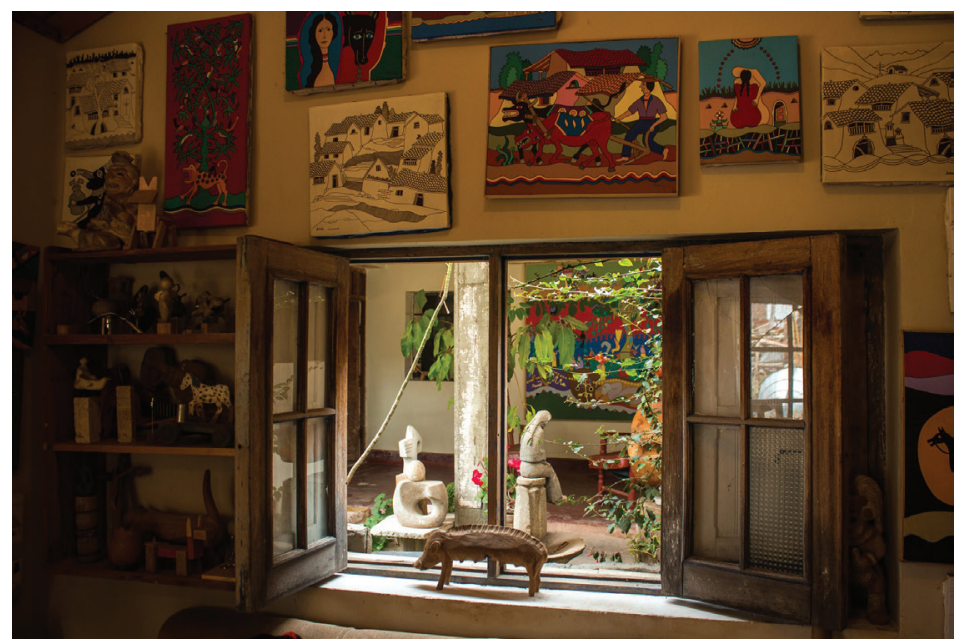

Figura 4. Ventana interior/exterior en el taller de Josué Sánchez en Huancayo Fotografía: Álvaro Iparraguirre Bernaola 
A continuación, revisaremos el trabajo del artista dividiéndolo en tres aspectos que resaltan y son constantes en sus trabajos: narrativa, mitología y simbolismos.

\section{Narrativa}

El trabajo de Josué Sánchez parte de situaciones cotidianas en el mundo rural: un grupo de personas cosechando, otro grupo de fiesta, otros más estudiando, etcétera. Este factor permite al público reconocer, construir y englobar cada elemento, dándole sentidos infinitos, pues, al ser algo cotidiano, se vuelve repetitivo a favor de la obra. Esta repetición hace posible establecer un patrón y marca un movimiento cíclico en la lectura narrativa. Además, no hay una lectura única ni un solo protagonista; todos los elementos de sus obras tienen el mismo peso visual y narrativo. Por lo tanto, se genera una coralidad que armoniza y de la cual todos forman parte, sin excepción, en una existencia imperturbable e infinita. Esta coralidad se relaciona con la formación musical que tuvo el artista durante su juventud y que, si bien no llegó a dedicarse a ello, hasta el día de hoy mantiene un consumo filarmónico bastante amplio. La armonía musical que respira el artista se puede percibir en sus trabajos a la hora de ordenar los elementos en escena.

Como si se tratara de un cuento, una pieza audiovisual de ficción o una canción, la pintura de Josué Sánchez tiene un trasfondo muy marcado, un subtexto, el cual ancla la obra en un determinado punto espacio-temporal. Además, es importante resaltar que, si bien el hombre es el centro de los trabajos de Sánchez, sus acciones y conexiones con la naturaleza son los ejes temáticos de su narración, siempre dentro de la cosmovisión andina: "En los modelos andinos, la relación hombre/naturaleza, cultura/naturaleza, individuo/colectividad, es inseparable del sentido de orientación" (Lizárraga, 1988, p. 53).

Otro pilar del mural de Sánchez, tal como ocurre en una narrativa básica de ficción donde el conflicto es la esencia del drama, es que presenta diversos elementos en disputa o, por lo menos, realizando actividades distintas en lugares distintos. SánchezEscalonilla (2014, p. 89) señala que el conflicto se halla en el núcleo de toda historia y es, ante todo, un problema que resolver. Una resolución que no es fácil ni estática y, como ocurre en el choque entre mundo andino y occidental, es constante. En el mural que analizamos, por los espacios y personajes que coexisten podemos decir que las imágenes están en un perpetuo conflicto al interactuar unas con otras, el pasado con el presente, lo andino con lo occidental, el mundo de arriba con el de aquí y con el de abajo. Nos muestra su punto de vista sobre la vida como un ente cíclico, de acción y reacción. Todos los personajes son activos, todos cumplen un rol. Sus actividades son interdependientes: se necesitan. A pesar de las separaciones de viñetas o escenas en la composición de la obra, los personajes y seres pueden transitar y eventualmente formar parte de otros escenarios (hay algunas escenas en las que la propia naturaleza cobra vida y forma parte de un mundo y a la vez de otro), pero ayuda a separar y establecer unas proporciones armónicas. 


\section{Mitología}

El artista ha investigado mucho sobre el tema y parece conocer cada historia y mito que se ha desarrollado en la sierra central. La construcción del mito del dios creador y de los dioses de las montañas (apus) da origen a un sinfín de historias con respecto a la creación. Dioses de los Andes como Wiracocha (el creador), la Pacha Mama (diosa de la tierra) y los apus son recurrentes en la obra de Josué Sánchez y están insertos en sus representaciones, como si formaran parte de una misma dimensión, en el mismo plano, pero a la vez no. Son seres vivos que vigilan, que miran, pero no se entrometen.

La cosmovisión andina cuenta con infinidad de historias y deidades, pero Sánchez se concentra en algunos, los cuales son constantes a lo largo de su obra. El principal ejemplo que podemos identificar es el del zorro. En la tradición oral recogida por Arguedas en Dioses y hombres de Huarochirí (1975), se cuenta la historia de "El zorro de arriba y el zorro de abajo", en la que ambos conversan y se preguntan el uno al otro cómo están. La situación que plantean es universal: el que vive abajo siempre está mal, lo que en un nivel simbólico puede interpretarse también en nuestras sociedades como la gran desigualdad económica y social que sufre nuestro país. Sin embargo, a pesar de la separación, que nos vuelve a remitir a la delimitación del mundo en Hanan Pacha y Uku Pacha, se deja abierta una posibilidad de diálogo en el Kay Pacha, donde habitamos. Según afirma Van Kessel (1994), "las leyendas andinas del zorro y de otros animales suelen cumplir con tres objetivos: entretener, moralizar y explicar" (p. 235) y de esta manera ocurre en la obra de Sánchez. Por lo tanto, sus murales son funcionales: nos cuentan algo, nos advierten y nos divierten.

\section{Simbolismos}

Sánchez usa elementos icónicos, muy comunes dentro del mundo andino y que se repiten en sus murales, como la serpiente de dos cabezas, que simboliza la venida de tiempos difíciles y de cambio. Otro elemento importante es la Cruz del Sur, representada con forma de rombo en los tejidos prehispánicos. Este rombo simboliza el corazón, el cual sería una representación del pueblo. Asimismo, puede ser dividido en dos, en referencia a la separación en la dinastía real inca de los linajes Hanan y Urin.

Como se mencionó anteriormente, el zorro es un elemento recurrente en la obra de Sánchez. En sus cuadros aparece en diferentes situaciones: feliz, con la cola gacha, y en otros en estado de atención, con la cola en alto. El zorro, como algunos otros animales silvestres, es considerado un animal del diablo en el mundo andino, tal y como afirma Van Kessel (1994). El zorro es un ser sabio, sabedor de secretos del hombre y del mundo en general. No es gratuito que en la obra de Sánchez cumpla la función de ser mediador: es quien más cercano está a una suerte de mezcla entre mundo real y mundo imaginario. Es quien, según otras leyendas, transita entre los dos mundos. Es el provocador del caos, 


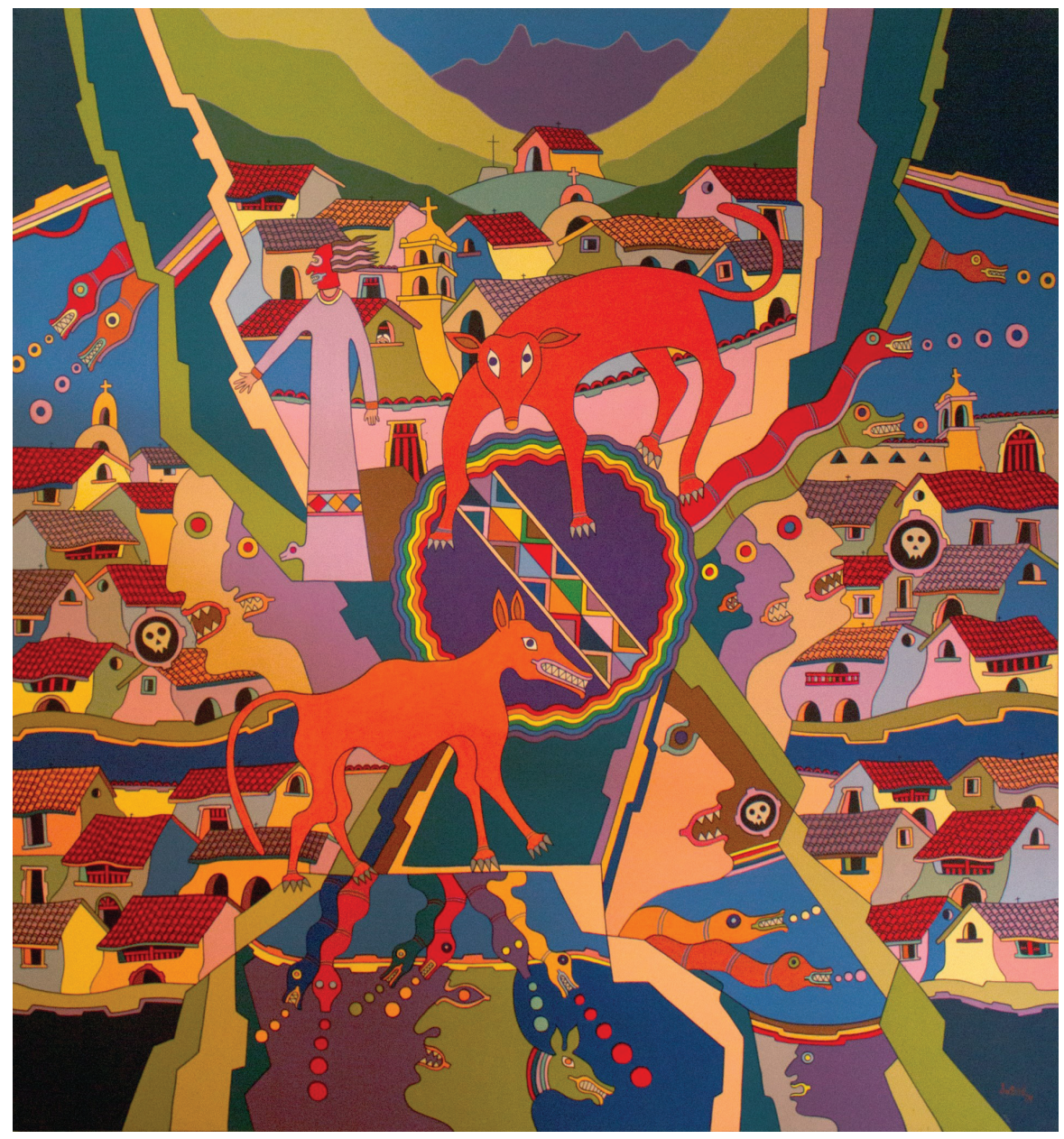

Figura 5. Zorro de arriba y zorro de abajo, de Josué Sánchez

Fotografía: Álvaro Iparraguirre Bernaola

pues, en su tránsito por el mundo "de acá", no conoce a ciencia cierta los códigos que se manejan y puede cometer errores, alterando el orden establecido.

En su obra, todos los elementos tienen vida y esta se esparce por el mural. Por ejemplo, el sol no solo cumple la función de dar calor y luz, no es una figura utilitaria, sino que tiene vida y se humaniza: es un personaje con rostro y vemos esa vida en los rayos presentes en el mural. Es así como Josué Sánchez, partiendo de sus experiencias con el entorno y de su mundo onírico, busca comunicar a través de sus colores, formas, trazos y demás. Todo con un estilo muy personal: "Es una búsqueda de la armonía y de plasmar la vida en su sentido más amplio" (Sánchez, comunicación personal, 16 de septiembre del 2017). 


\section{MÁS ALLÁ DE LAS IMÁGENES: HACIA UNA ESCRITURA VISUAL}

Escribir para mí no es fácil. Yo no escribo, pinto. Hoy mis cuadros hablarán por mí.

(Sánchez, 2006)

Uno de los aspectos que más llama la atención al analizar la obra de Josué Sánchez es la manera como estructura la sociedad que representa. Las diferencias están presentes, pero son parte de un todo, como si cada elemento alterara la realidad, sin excepción. Cada uno va construyendo desde su espacio, pero, finalmente, llega a influir en el del otro para formar una interdependencia: los vendedores de papas necesitan que los agricultores cultiven sus papas, así como el consumidor de estas necesita de los comerciantes, etcétera. Este mundo dividido en tres, propio de la cosmovisión andina, se convierte en una sola unidad, donde pareciera que naturaleza, animales y humanos se encuentran en perfecta armonía. Pero esto no necesariamente significa que no exista conflicto; más bien, es parte de ese mundo. "En mi pintura se reflejan los tres espacios. No siempre separados: a veces se juntan, porque la vida de la persona está gobernada por los tres. Hay ritos, cuentos, que lo explican", comenta Sánchez (González, 2014).

La distinción del arte de Josué Sánchez reside en la construcción de relatos en las imágenes. No solo por el movimiento y la imagen en sí, sino por lo que está detrás, lo que busca significar: a manera de una escritura visual. No en vano es urgente preservar todo tipo de arte narrativo, pues es y ha sido el principal vehículo de comunicación hacia las nuevas generaciones, en una búsqueda de renovar y preservar el saber y los sentires (Van Kessel, 1994, p. 241).

La integración es la base de nuestro futuro, y Sánchez tampoco es ajeno al mundo de Occidente, más bien busca integrarlo. Incluso en países como Alemania, donde se pueden encontrar obras suyas, sus murales han sido incorporados al contexto en donde se muestran, santuarios e iglesias, pero siempre es fiel a su estilo y discurso, pintando y representando la cotidianidad del mundo andino, como el ciclo agrícola y ganadero de los Andes. Sánchez sostiene:

Mi intención ha sido mostrar la potencia del arte que recupera la tradición, que trata de entrar en diálogo, o enraizarse, en lo indígena. Esta vitalidad certifica que la sociedad peruana no podrá construirse como nación hasta que no se haga un lugar en lo andino y sus proyecciones en la cultura de la migración. (Portocarrero, 2015, p. 11) 


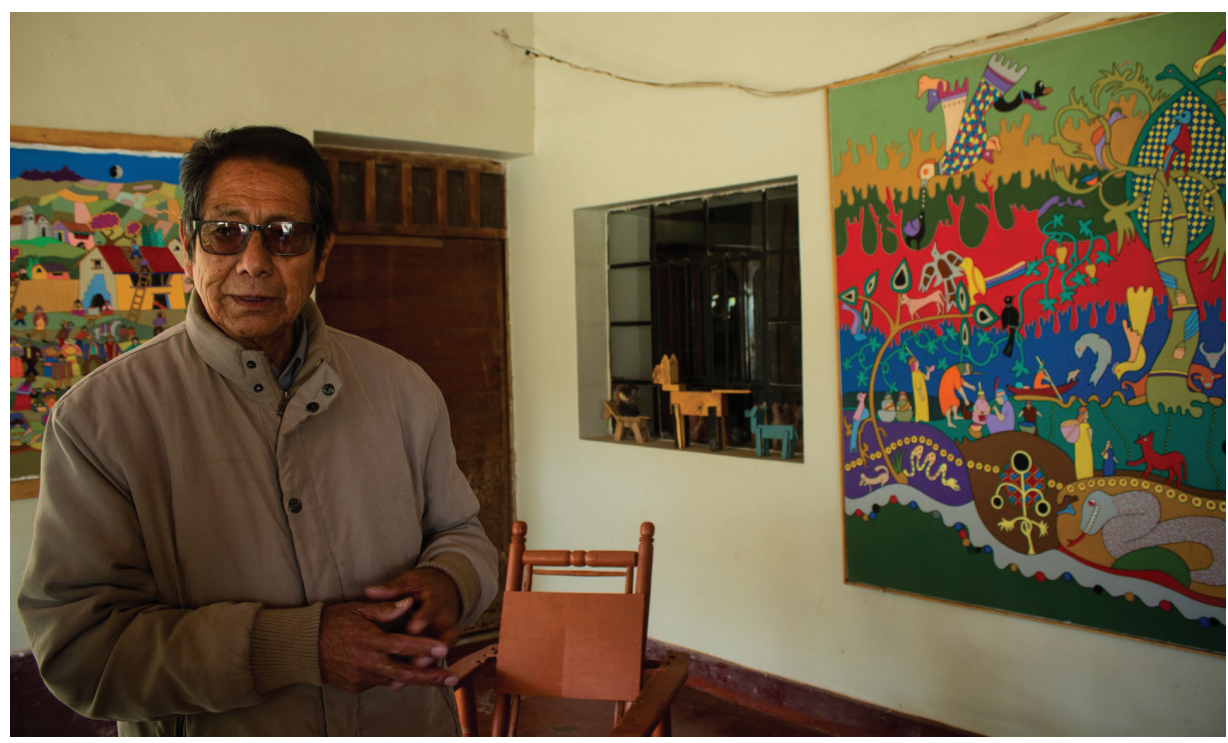

Figura 6. Josué Sánchez, en su hogar, mostrándonos sus trabajos

Fotografía: Álvaro Iparraguirre Bernaola

Josué no se considera un indigenista, no plasma una mirada compasiva ni dramática sobre el mundo andino. No es un visitante, sino un local; tiene una mirada desde adentro, desde la de un hombre que vive y respira la sierra central en su totalidad. Al conversar con el artista, surge la palabra peruanista como una alternativa que podría representar mejor una posible corriente:

Cada autor inventa o propone su propia línea de trabajo y su código personal. Ellos conceden más importancia a la imaginación y a la fantasía y, sobre todo, al descubrimiento de la dimensión oculta y contradictoria del alma humana. $Y$, cuando exploran el imaginario andino, lo hacen buscando revelar el sustrato mítico y la visión cósmica de raíz prehispánica. Esto explica que el arte en el valle del Mantaro sea ahora más rico y complejo, con una gran diversidad de lenguajes, técnicas y formas que no tuvieron las escuelas realista, costumbrista e indigenista. (Baquerizo, 2009)

Ahora Sánchez repite a sus alumnos de arte lo que Marina Núñez del Prado, reconocida escultora boliviana, le dijo para animarlo a persistir en su trabajo frente a las duras críticas que le hicieron los profesores de la Escuela de Bellas Artes de Lima en su primera exposición importante en la capital, al encontrar insoportable su pintura plana y su uso del color: "Solo un arte con identidad puede ser universal" (Sánchez, 2006). Y eso bastó para encomendarse en la misión de consolidar un estilo basado en una estética andina. 
Vale recordar las palabras escritas por Trotski y Breton, luego suscritas por Diego Rivera, sobre el arte revolucionario independiente:

El arte no puede someterse sin decaer a ninguna directiva externa y llenar dócilmente los marcos que algunos creen poder imponerle con fines pragmáticos extremadamente cortos. Vale más confiar en el don de prefiguración que constituye el patrimonio de todo artista auténtico, que implica un comienzo de superación (virtual) de las más graves contradicciones de su época y orienta el pensamiento de sus contemporáneos hacia la urgencia de la instauración de un orden nuevo. (Breton, Rivera y Trotski, 1938)

Sánchez es un artista consecuente con sus principios y fiel a lo que propone. No está suscrito a alguna corriente determinada y, tal como retrata en su obra, por encima de todo está la libertad, libertad no solo de forma, sino también de contenido. No pretende ser considerado como un artista "suave"; su intención no es ser uno más, pues no se trata de solo pintar bonito. "Si no hay crítica, no hay nada", comenta (comunicación personal, 16 de septiembre del 2017).

Los ideales se transmiten a través de las realidades y problemáticas que el artista plantea en su obra. A pesar de ello y de los numerosos años que lleva en el medio, a Josué Sánchez aún le cuesta exhibir sus obras en la urbe. Si bien los circuitos alternativos de exposición artística y cultural se empiezan a expandir y reproducir, ofreciendo espacios a nuevas y diferentes voces, el mundo del arte sigue siendo un medio bastante cerrado, con acceso restringido y configurado para los grupos que ya están establecidos o consolidados. La trascendencia de los artistas y sus obras en el tiempo estará supeditada al juicio fuera de las galerías, en contacto con la gente, con el pueblo, con la realidad. Realidad que aún nos negamos a ver, aunque poco a poco las vendas van cayendo; y es trabajo de todos y todas el desatarlas.

Más que nunca cobra relevancia la incógnita que planteaba Arguedas y que recoge Josué Sánchez en su mural de la Casa de la Literatura Peruana: "Y el Perú, ¿qué?".

\section{REFERENCIAS}

Acevedo, J. (6 de agosto del 2013). El Cuy TV con Josué Sánchez [entrevista, archivo de video]. Recuperado de https://www.youtube.com/watch?v=TK4g65NRCeY

Aponte Isaza, M. C. (enero-junio del 2016). Función social del arte. Aporte de la obra de la artista Doris Salcedo al proceso de justicia transicional en Colombia. Revista Científica General José María Córdova, 14(17), 85-127. Recuperado de http://www. scielo.org.co/pdf/recig/v14n17/v14n17a05.pdf

Arguedas, J. M. (1975). Dioses y hombres de Huarochirí. Ciudad de México, Madrid, Buenos Aires: Siglo Veintiuno Editores. 
Artífice Comunicadores. (24 de noviembre del 2014). Josué Sánchez, pintor del mundo andino. Identidades Peruanas. Recuperado de http://identidadesperuanas. com/2014/11/josue-sanchez-pintor-del-mundo-andino/

Baquerizo, M. (24 de octubre del 2009). Las artes plásticas en la región central. Diario Correo. Recuperado de http://diariocorreo.pe/espectaculos/las-artesplasticas-en-la-region-central-155792/

Batalla, C. (9 de noviembre del 2001). Un huanca de colección. El Peruano. Recuperado de http://www.circle-24.com/c24pages/kjs_varios_comentarios_mas.html

Breton, A., Rivera, D., y Trotski, L. (25 de julio de 1938). Manifiesto por un arte revolucionario independiente. Recuperado de http://sgpwe.izt.uam.mx/files/users/uami/nivon/ BRETON_manifiestopdf.pdf

Casa de la Literatura Peruana. (22 de julio del 2015). Presentación del proyecto Nueva Exposición Permanente de la Casa de la Literatura. Recuperado de http://www. casadelaliteratura.gob.pe/?p=16764

Cauna, Y. (8 de octubre de 2014). Josué Sánchez y la herencia pluricultural. LaMula.pe. Recuperado de https://tvrobles.lamula.pe/2014/10/08/josue-sanchez-y-la-her encia-pluricultural/tvrobles/

¿Cómo se autoidentifican los peruanos? Los resultados del censo del INEl. (11 de septiembre del 2018). RPP Noticias. Recuperado de https://rpp.pe/peru/ actualidad/como-se-autoidentifican-los-peruanos-los-resultados-de-laencuesta-del-censo-2017-del-inei-noticia-1149183

Desrosiers, S. (1997). Lógicas textiles y lógicas culturales en los Andes. En T. Bouysse Cassagne (Ed.), Saberes y memorias en los Andes. In memoriam Thierry Saignes. París: Éditions de l'IHEAL. doi:10.4000/books.iheal.825

Díaz, J. (2003). Pintura y cosmovisión andina: Josué Sánchez. En G. Espino (Comp.), Tradición oral, culturas peruanas: una invitación al debate (pp. 285-290). Lima: Universidad Nacional Mayor de San Marcos, Fondo Editorial. Recuperado de http://sisbib. unmsm.edu.pe/BibVirtualData/libros/Literatura/trad_oral/diaz_mj.pdf

Espinosa, A. (2010). Estudios sobre identidad nacional en el Perú y sus correlatos psicológicos, sociales y culturales (tesis doctoral). Recuperado de https://www.researchgate. net/profile/Agustin_Espinosa3/publication/277141441_ESTUDIOS_SOBRE_ IDENTIDAD_NACIONAL_EN_EL_PERU_Y_SUS_CORRELATOS_PSICOLOGICOS_ SOCIALES_Y_CULTURALES/links/556360c308ae6f4dcc98b5b3.pdf

Espinosa, A., y Rottenbacher, J. (2010). Identidad nacional y memoria histórica colectiva en el Perú. Un estudio exploratorio. Revista de Psicología, 28(1), 147-174. https:// doi.org/10.18800/psico.201001.005 
Golte, J. (1992). Cultura y naturaleza andinas. En E. Kingman (Ed.), Ciudades de los Andes: visión histórica y contemporánea. Lima: Instituto Francés de Estudios Andinos. doi:10.4000/books.ifea.2264

González, V. (26 de octubre del 2014). El arte y lo social andino. Diario Uno. Recuperado de http://diariouno.pe/el-arte-y-lo-social-andino/

Kingman, E. (1992). Ciudades de los Andes: homogeneización y diversidad. En E. Kingman (Ed.), Ciudades de los Andes: visión histórica y contemporánea. Lima: Instituto Francés de Estudios Andinos. doi:10.4000/books.ifea.2241

Lauer, M. (1982). Crítica de la artesanía: plástica y sociedad en los Andes peruanos. Lima: Desco, Centro de Estudios y Promoción del Desarrollo.

Lauer, M. (2007). Introducción a la pintura peruana del siglo xx. Lima: Universidad Ricardo Palma.

Lizárraga, K. (1988). Identidad nacional y estética andina: una teoría peruana del arte. Lima: Alhambra.

Melia, B. (1975). Para una historia de la evangelización en América Latina. En Para una historia de la evangelización en América Latina, III Encuentro Latinoamericano de CEHILA, Santo Domingo (pp. 11-32). Barcelona: Hogar del Libro.

Milla, Z. (1990). Introducción a la semiótica del diseño andino precolombino. Lima: Eximpress; Concytec.

Pinto, J. P. (1992). La fuerza de la palabra. Evangelización y resistencia indígena. En S. Arze, R. Barragán, L. Escobari, y X. Medinaceli (Eds.), Etnicidad, economía y simbolismo en los Andes: II Congreso Internacional de Etnohistoria. Coroico. Lima: Instituto Francés de Estudios Andinos. doi:10.4000/books.ifea.2297

Portocarrero, G. (2015). Objetivaciones de lo andino y lo peruano en Josué Sánchez y José María Arguedas. En Imaginando al Perú: búsquedas desde lo andino en arte y literatura. Lima: Pontificia Universidad Católica del Perú, Instituto Riva-Agüero.

Salles, V. (1992). Buscando armonía en dos universos religiosos. En S. Arze, R. Barragán, L. Escobari, y X. Medinaceli (Eds.), Etnicidad, economía y simbolismo en los Andes: Il Congreso Internacional de Etnohistoria. Coroico. Lima: Instituto Francés de Estudios Andinos. doi:10.4000/books.ifea.2308

Sánchez, J. (31 de octubre del 2006). Todavía no pinto canas [blog]. Recuperado de http:// news.bbc.co.uk/hi/spanish/forums/espacio_del_lector/newsid_6064000/ 6064048.stm

Sánchez-Escalonilla, A. (2014). Estrategias de guion cinematográfico. Madrid: Ciencias Sociales Ariel. 
Santos, A. (2009). Cosmovisión y religiosidad andina: una dinámica histórica de encuentros, desencuentros y reencuentros. Espaço Ameríndio, 3(1), 84-99. Recuperado de https://seer.ufrgs.br/EspacoAmerindio/article/viewFile/8431/5253

Van Kessel, J. J. M. M. (1994). El zorro en la cosmovisión andina. Revista Chungara, 26(2), 233-242. Recuperado de http://www.chungara.cl/Vols/1994/Vol26-2/El_zorro_ en_la_cosmovision_andina.pdf 